\title{
"It's Better That She Sees Me:" Digital Visual Literacy Narratives of Women Immigrants in Chile and Implications for Adult Literacy
}

Sondra Cuban, Western Washington University

Jo Ann Arinder, Washington State University

Acknowledgements: A version of this article is drawn from the authors' paper presentation at AERA 2019

\section{Abstract}

Narratives drawn from a Fulbright study of immigrant women in Chile communicating with their families at-a-distance through information and communication technologies show that they utilized digital visual literacy practices. Digital visual literacy is a combination of digital literacy and visual literacy and even goes beyond these conceptualizations. By manipulating their levels of visibility through platforms on smartphone devices, immigrant women strove to create a sense of co-presence with their families abroad. This paper demonstrates the complexity and relevance of combining visuality with multi-literacies, voice, and gendered narratives of digital communication for immigrants inside and outside of adult literacy classrooms.

Keywords: information and communication technologies, digital literacy, immigrants, visual literacy, transnational families

This study is about the ways immigrants communicate with their transnational families through information and communication technologies (ICTs), especially smartphones. This phenomenon is important to study because of the increase in migration where more families are separated than ever before. Yet they want to see one another and feel a sense of connection from afar. This article presents the visual aspects of this ICT-based communication and the ways that migrants control their visibility with their family members at-a-distance. We focus on the ways they navigate the visual aspects of electronic family communications or digital visual literacy (DVL).

DVL is generally defined as the ability to critically evaluate visual materials, including moving and 3D images in a digital environment, make decisions on the basis of digital visual representations; and use devices to create effective visual communications (Spalter \& Andries, 2008; Martin et al., 2008). We asked the following questions to illuminate the phenomenon of DVL within transnational family communication: 
- What are the experiences of women immigrants in communicating with their families through ICTs from afar?

- What are the digital visual practices they use to navigate their communication that impacts their visibility and sense of presence?

- What demographic, geographic, and technological factors affect this communication?

We developed themes of DVL and exemplary profiles of immigrant women's stories of communicating with their transnational families. Three immigrant women's narratives are profiled in this article along with themes of DVL that represented 55 immigrant women from Latin American and Caribbean (LAC) countries who were participants in a Fulbright Commission study that took place in Chile. Cuban conducted the study in 2017, collaborating with the Ministerio de la Mujer y la Equidad de Cénero (Ministry of Women \& Gender Equity), as well as Chilean and migrant academics and activists. Afterwards, Cuban and Arinder analyzed the data.

\section{Examining DVL within the Context of Chile}

Chile is historically known as an immigrant sending country, particularly during the Pinochet regime when thousands of Chileans fled persecution (1973-1990). Yet since the 2010s, Chile has become one of the fastest growing receiving countries for immigrants in the LAC region and in the world (Dona-Reveco, 2018; UN DESA, 2017). Known as an "economic jaguar," Chile's reputation as a secure and successful South American country has drawn about 1.5 million immigrants, mostly from the LAC region and about half of who are women (Cabieses et al. , 2013; DoñaReveco \& Levinson, 2012). Since 2014, Haitians,
Colombians, and Venezuelans fleeing natural disasters, politically unstable governments, and weakened economies have been the newest immigrants, while nearby Argentinians and Peruvians have moved back and forth from chile for over a century. The new immigrants typically know little about Chile's social inequalities and that its democratic institutions and economy are more fragile than its "Chilean miracle" reputation (Richards, 2013, p. 1). Its privatized health, education, and social services, together with a segmented low-wage labor market and a lack of citizenship pathways have made LAC immigrants' social and occupational mobility especially difficult (Stefoni \& Fernández, 2011). Plus, gender and racial barriers in Chile, stemming from a patriarchal, Europeanized, colonial history heavily impact new immigrants' integration into society particularly those of Afro-descendant backgrounds (Tijoux, 2015). Generally, socio-economic policies have been slow to adapt to Chile's diverse and growing immigrant communities.

Against this backdrop of inequalities, this study focuses on women immigrants' transnational relations through examining their longdistance family communication via ICTs, on smartphone devices and Wi-Fi-based social media platforms. We examine the uses of these ICTs by immigrant women from LAC countries with their family members who were separated through migration and the role of digital visuality in their communications. The phenomenon that we explore is likely shared by other immigrants moving to destinations like the United States. Their visual navigation, combining talk, text, images, and media involved considerable emotional labor. Emotional labor is a concept in the sociological literature that focuses on the ways that women manage their relations and meet other people's needs through behaviors 
such as smiling and comforting, especially in the workplace (Hochschild, 1983). ICT researchers (Baldassar, 2008; Madianou \& Miller, 2012) have highlighted how emotional labor also occurs in high tech personal communications. This emotional work on the part of women immigrants with their families has less to do with their skills or education levels, and more to do with their gender, resources, practices, and family circumstances. As the three profiles and the themes illuminate, some participants in the study showed their families everything and broadcasted information, while others did not want to be revealed at all, or only partially disclosed personal information. This is what we mean by DVL. These DVL interactions involve complicated, intimate, navigational reading practices and this study focuses on the factors underlying this phenomenon within ICT-based transnational family communication.

\section{Transnational Families, Communication, and ICTs}

The qualities of long-distance communication between immigrants and their family members, is based on a burgeoning literature on migration and new media (Baldassar, 2008; Cuban, 2017, in press; Madianou \& Miller, 2012; Nedelcu \& Soysüren, 2020; Parreñas, 2008; Wilding, 2006). These researchers focus on immigrants communicating with their families through ICTs, particularly the ways they attempt to bridge social distance at-a-distance and the cultural and psychological effects of such communication in addition to their exchange of care and support. Only a few researchers however focus on the problematic aspects of the ICT-based transnational communication like navigational difficulties, technical connectivity, and the inequalities associated with ICTs-the infrastructure and resources needed to access, use, and maintain such long-distance interactions (Cuban, 2017; Madinaou, 2016; Wilding, 2006). Even with visual displays, locational media, sophisticated audio features, and apps, family members often find it difficult to read each other's moods and feelings through the screens and subsequently experience only a "semblance" of intimacy (Parreñas, 2005, p. 334). These researchers therefore characterize the communication as "blessings and burdens" (Horst, 2006, p. 143). This is because of the lack of touch, the ambient screen environment, geographical distance, the resources necessary to access and use new technologies, and the different contexts and time zones which are not overcome by the speed and immediacy of the ICTs (Cuban, 2017). After all, "contact and connection are not the same thing" (Hannaford, 2015, p. 46).

Nonetheless, family members strive to connect to one another as best as they can. As mobile phones and computers are increasingly popular and user-friendly, visual features, too, are also important in creating a "shared world in which the interpersonal relationship is constituted" (Licoppe 2004, p. 138). Researchers have coined an outcome of these interactions as "ordinary co-presence” (Nedelcu \& Wyss, 2016, p. 203) or “connected presence” (Licoppe, 2004, p. 135), which is defined as, "the condition of reciprocal orientation that is related to the potential for social interaction" (Palackal et al. 2011, p. 394). This observable co-presence with other members at a distance, includes a sense of being there for family members through ICTs (Baldassar et al, 2016). In part this is because the more the technological interfaces are mapped to the senses, the more a believable augmented reality seems to be created for users (Biocca, 1997). As we shall see immigrant women understand the imperfection of the ICTs and manipulate their levels of visibility with family members, sometimes appearing and 
disappearing in a smartphone world where there is "limitless accessibility and manic connectivity" (Agger, 2011, p. 223).

The visuality in today's communication is omnipresent. In the past, when immigrants left their homes and families they were in little contact, if at all. The contact was mainly through textual/print means (like, sending letters) and then later, also, via audio/audial (phone voice calls and voice recordings) (Madianou \& Miller, 2012). Visual communications were never possible unless visits were made, photographs were sent, or members described in detail what something looked like, words to be sealed in the imagination of the receiver.

\section{Our DVL Framework}

The visuality embedded in digital communication, including social, cultural and sensory interactions surrounding seeing, is important to examine because nearly all of the participants used smartphones hosting integrated functions to communicate with their families on social media platforms that combined text, audio, and images. Yet the DVL literature is more about the how-to aspects of visuality, for professional purposes, and, with an emphasis on computer platforms, ranging from altering images in Photoshop, to video gaming, to software programs, including computer aided drafting (MacGregor, 2013; Mirzoeff, 2006). Little research has focused on DVL as a sociocultural practice, for family communication, and on mobile phone devices. We, therefore, rely on a conceptualization of DVL that is personal, openended, and less device-centric:

the ability to critically read, understand and analyze and to produce meaning from information and messages presented in visual, digital texts, to communicate and transmit visual messages effectively, to create and produce presentations expressing visual messages, by consideration and selection of how to present them. (Avni \& Rotem, 2016, p. 40)
DVL is a combination of both digital literacy and visual literacy and even goes beyond these conceptualizations. Digital literacy research typically includes multimedia, but there is a heavy focus on texts that are produced, distributed, received, and exchanged through digital means (Guillen, 2014; Lankshear \& Knobel, 2008). Visual literacy on the other hand focuses on imagery, with the purpose of "learning new and more sophisticated ways to analyze and use images" (Kovalchick \& Dawson, 2004, p. 124). Our research moves beyond a focus on either text or imagery, or technology skills, to highlight the social practices of transnational families' ICT uses that engage all aspects of audio, textual, and visual communication.

DVL also depends on technological affordances, especially infrastructure, funds, network connections, and equipment to maintain ICTbased family interactions at a distance (Parchoma \& Wright, 2011). This aspect is also missing in the DVL literature. While some members have more experience and access to a variety of multimodal technologies, others have very limited access to these same technologies. Social affordances are also important; these are social characteristics like culture and gender associated with interacting through multi-media ICTs (Latour, 1999). Immigrant women participants in this study were found to differentially exploit their social and technological affordances so as to spread their presence over geographic distances within digital environments. Our DVL concept, then, takes the user past simply interpreting visual input to focusing on it holistically with other modes of communication, and through access, use, resources, and contexts.

Our conceptualization releases DVL from particular devices that are place-bound (computers) turning it into a mobile concept (through hand-held 
devices), and which is critical for personal communications, as well as remote instruction as in the COVID-19 crisis. As we shall see, DVL is activated when family members call one another on mobile phones and interact. In this case, computers are no longer a necessary component of DVL. In fact, most functions that users employ to communicate are available through a phone in the back pocket. The phone then becomes a key factor for our focus on DVL as part of women immigrants' cross-border communication. Yet it is not the phone alone, but these members' emotional labor, time, money, and commitments to call that create the "social glue" (Vertovec, 2004, p. 219) that keeps the family ties active. DVL then becomes part of a complex web of long-distance family communication that centralizes visual experiences through screens, along with other modes, and which multiplies and accelerates transnational communications (Jiménez et al., 2009).

DVL in this context is also nuanced. It happens when family members navigate their screens together to make "an active, creative mode of vision" whereby everyone's eyes move and track colors, shapes, and spaces through talking and sharing information (Verhoeff, 2012, p. 13). They also map facial expressions to interpret feelings, which operate below the surface of the screens. DVL then can be "highly selective and interrupted" (du Preez, 2018, p. 85). Screens too can "shield from the vulnerability of visual engagement" especially when information is controversial (Verhoeff, 2012, p. 14). In this way, "subscreenic literacies" emerge that abbreviate visual communication (Lynch, 2017, p. 92). Understanding these varying levels of DVL might "offer a better understanding of how the cultural uses of digital spaces shape the ways [families] use language and, ultimately, experience the world around them" (Gilhooly \& Lee, 2014, p. 389). Importantly, all of the participants owned phones and were active and deft in navigating their communications with their away-families and none of the participants claimed to have problems communicating with them due to lacking skills.

\section{Study Methods and Sample}

This exploratory study used narrative interviews, observations, and visual artifacts. A sociodemographic analysis of the sample allowed us to glean patterns about the participants across various characteristics. Fifty-five immigrant women participants were selected to represent Chile's current immigrant population. The participants were recruited through a variety of places, including streets, bus terminals, Spanish language courses, non-profit organizations, and government institutions, like the Ministry. Participants also recruited one another through a snowball approach, whereby one participant mentions the study to a prospective one. Most participants came from: Haiti (13), Colombia (13), and Venezuela (9). Six participants were Mexican, most of them attending Chiles' universities. There were three Argentinians, two Peruvians, two Cubans and five Ecuadorians. Additionally, there was one participant each from both Brazil and Uruguay. Most participants were in their mid-3os, with varying levels of education, work histories, marital status, number of children, and arrival times. About half of the participants had partners or were married and had children. Twenty-one of the participants possessed university degrees, several of who were attending post-graduate programs in Chile. Several more dropped out of their university studies before graduating in their countries, only one of them attending a university program in Chile. Furthermore, there were four international exchange students from Mexico. Thus, the sample represents women's greater access 
to $\mathrm{K}-16$ education in the $\mathrm{LAC}$ region which is generally high (Maldonado-Maldonado \& Felicitas Acosta, 2018). Ten participants had high school diplomas, with several more receiving 2-year technical degrees or certificates in Chile, and one participant attended a high school diploma program. Seven participants did not complete high school and four additional participants had a primary or middle school education. None of these participants continued their formal schooling in Chile. Nearly all of the Haitians attended community-based Spanish courses.

The interviews, delivered in Spanish and HaitianCreole by the researcher and translators, lasted around 1 hour and focused on participants' stories of their transnational communication and relations with families back home through ICTs, especially the visual aspects, and which encapsulated the central purpose of this study. The narrative interviews and the narrative analysis and resulting profiles and themes, probed deeply into the participants' experiences on intimate, mundane, and often undisclosed subjects (such as communicating with family), and were important for revealing their transnational identities and belonging (Dwyer et al., 2017). Our approach incorporated the performative aspects of their transnational communication which involved their "electronic emotions" including the ways they presented themselves to their families far away (Silva, 2012, p. 158). The participants discussed what it meant to see and interact with their families through ICTs and their meanings. The profiles and themes focused on the problematic aspects of DVL and transnational family communication to reveal the "breach between ideal and real, self, and society" (Riessman, 1993, p. 3).

We also collected visual materials that represented the participants' lives back home, especially photographs and videos. These artifacts, with their visual power, supplemented the interviews and illuminated the participants' cultural and family biographies. They discussed what these artifacts meant, and how they felt they contributed to their livelihoods and communications as well as family memories (Pahl, 2012; Pink, 2009). A web-based story platform called MapMe was then used to connect the visual data with the interviews and sociodemographic analysis. MapMe had an easy interface and did not require coding skills to input the data. Following the menu and clicking we could transfer all of the data, organize it, and then store it. The system offered a glimpse into the participants' worlds beyond chile and allowed us to develop a transnational perspective on their families and their communications. This analysis also allowed for a reflexive discussion to emerge between the researchers about the difficulties we experienced communicating with our families from far away.

\section{Profiles and Themes of DVL}

Through our analysis we found that the participants navigated their interactions effectively through a range of high, mid, and low visibility levels in an attempt to achieve co-presence with their family members. Their manipulation of imagery on screens involved their native languages, their affordances, and navigational techniques that were embedded in gendered norms. The following profiles and themes demonstrate that regardless of the education levels, participants were savvy in operating their phones and communicating with their families to achieve co-presence from far away. We use profiles of three different participants to give a close-up view of how the DVL phenomenon varied within transnational 
family communication as well as themes that represented the 55 participants; for each of the three participants' profiles, we provide additional anecdotal evidence from other participants whose experiences fit these themes.

\section{DVL Profile of Carmen and Theme: High Visibility, Ample Social Media, and Native Language Videocalls}

Carmen, in her early 2os, was a journalism student at a Mexican university. She desired a career in film, "because I like doing that work-audiovisual." In migrating to Chile as an exchange student she said, "to travel and know a culture, it really makes you realize about living somewhere different from where you grew up... and that made me want to leave Mexico." However, she acknowledged, "it scared me the most to leave my comfort zone." Her mother was worried about losing her youngest daughter: "Whenever I call her on the phone," Carmen noted, "she wants to talk on videocall and right away she wants to show me whoever is around. For her, it's better that she sees me." Seeing her daughter while speaking to her on videocalls, made her mother feel "calm--to see she is processing much better that I am far away." So, Carmen called her at least every other day. Through these calls, her mother was "getting used to the idea of me being far away." While she spoke with her mother on video through Facebook she interacted with her sisters on a daily basis through WhatsApp and mainly through texts and calls. While she had to consider the cost, it was not a barrier to her communication. She said, "I got a phone [but] they don't allow me to unlock it, so it costs me a lot more money if I don't have the Internet." Between short gaps in communication, she looked at a treasured photograph she brought of her extended family which reminded her that although she was away, she was still central to her family unit.
Theme of high visibility across participants. Carmen's videocalls revealed the importance of having a highly visible presence with family members. She could interact in Mexican Spanish and her local dialect, with idioms and expressions that were familiar. It is important to note that Spanish variations accounted for an initial struggle Carmen and other LAC participants had in mastering the Chilean dialect, which contains distinct grammar, pronunciation, and vocabulary, and which had to be adapted by the participants to be understood by Chileans. A number of the participants, particularly, Mexicans, complained about being discriminated against, and laughed at for their Mexican Spanish and the students suffered from stereotypes, by Chilean students and professors, as partyers. One Mexican participant, claimed Chileans shouted, "tacos, and beer, let's go party" sort of thing... they yell, "tacos and cabrón." The idiomatic expressions slang and accents across the LAC region were quite different. In the case of Brazilian, Haitian, or Ecuadorian indigenous participants, whose first languages were not Spanish, connecting with family and using their first languages and forms of expressions were key to maintaining their cultural identities. All of those with minoritized dialects or languages in Chile felt more comfortable communicating with their transnational families especially during videocalls that allowed them to use familiar expressions in the vernacular and gestures that were easily understood and didn't have to be explained.

Recall Carmen used different video calling platforms, through WhatsApp with friends and sisters of her generation and Facebook, an older platform, with her mother. WhatsApp was particularly popular, being specifically mentioned by 21 participants, due to its fully integrated functions, enabling greater access points, as well as speed of contact, and the fact 
that its user-friendly features utilized free Wi-Fi/ broadband, which both Carmen and her family as well as other users had on both sides of the border. Manipulating these features enabled native language voice and literacy to flourish together while simultaneously increasing demands from family for more interactions. So, the participants' parents, in having one videocall, often demanded more as well as longer periods of talking and seeing their daughters.

Visual artifact exchanges, like photographs, supplemented textual and audio/ videoconferencing interactions on WhatsApp, and also contributed to the cultural management of separated family members. With access to Wi-Fi, exchanging videos, messages, and photos was typical and often increased with more contact. Texting, voice calls, and voice messaging were also utilized. One Colombian participant, remarked, "I am grateful for the technology, that it was advanced through WhatsApp, voice messages, and I see them in video chat and that helps me to stay connected to my roots." Participants often preferred videocalls because they said they could "see" their family which was a plus vs. just using voice and listening through phone calls. Another Colombian participant stated that the group call was an excellent way to achieve co-presence: "She sees us, and we see her and since she's with my dad there we also see him." Some participants rejected videocalls for this very reason because it reminded them of how far apart they were, like one participant's videocalls that were "tough, we would talk on video and cry and cry."

\section{DVL Profile of Pilar and Theme:} Mid-Visibility, Rural Areas, and a Lack of Technological Affordances

Pilar, like Carmen, was also in her 2os. Unlike Carmen, however, she never made it to high school and dropped out of middle school to work in an agricultural processing plant. She had also lived alone since twelve because of the financial difficulties of her parents. She was raised in the Canton Antonio Ante located in the Province of Imbabura, Ecuador and was indigenous Otavaleña. Pilar had a 6-year-old daughter, who she left in Ecuador with them. She had been in Chile less than a year, explaining: because "the economy in Ecuador is what forces us to migrate leaving all our loved ones behind." Pilar had her daughter when she was 17 under dire circumstances, "because I got raped." Coming to Chile was an opportunity she felt she had to grasp, when she was offered a domestic post by a Chilean family she met in Ecuador, "they offered me a job but I needed to travel, so I didn't think it twice and I came." Pilar was currently a street vendor and made clear that, "the purpose of now being here in Chile is to eventually bring my daughter, so that she can be here with me because having her in my country alone is very complicated and on top of that I'm also her dad." She kept in touch with her daughter through WhatsApp "video chat" and only briefly greeted the rest of her family. She explained the effect of contacting them: "The reward I get from talking to my family is to hear them say 'yes, we are good, we just want you to take care of yourself, God is with you and we are waiting for you to come back soon'." She did not want to talk much with her mother who she felt "suffocated" her as a teen and pushed her out of the house early to work. She called her daughter so she had a presence in her life, explaining: "I try to call twice a week since I've been here so my daughter doesn't forget me so that she won't tell me that I'm not her mom, because she's said that to me, that I'm not her mom because I'm not there with her."

Theme of mid-visibility across the participants. Participants with family from rural areas, like in 
Pilar's case, had less income and could not call or pick up the phone as regularly due to data, cost, and infrastructural issues. The cost of maintaining regular service, or any service at all, prohibited regular voice calls or videocall communication. While lack of technological infrastructure seems an obvious factor of country living, it was more influenced by the economic status (as well as family income) of the participant and the family left behind. Most of the gap in digital technologies of the participants appeared to wrest on financial resources to communicate. For other participants, particularly those with family in rural areas or in countries with less advanced infrastructure, the communicative maintenance was not simple.

One Venezuelan participant's parents were living in the countryside and there was no regular way to stay in contact with them. She had to wait until someone travelled to visit them in order to contact them through voice calls: "Every 15 days, when my niece visits [my parents] and she lets me know, and I can talk to them. Otherwise I wouldn't know about them." Another Venezuelan participant communicated regularly with her father but it was not without difficulties. She spoke once a week to him and noted that "the Internet is really bad. It's not blocked communication---it gets cut off and there is no signal and it's difficult with the Internet." A Haitian participant tried to stay in touch with her son who lived with his grandmother in a rural area. While she had Wi-Fi access in Chile the access was not the same back in Haiti: “The biggest issue now is that I can't communicate with my son because they live in a province and that province has no signal." Another area where the location of family created a barrier to communication was Cuba. A Cuban participant talked to her mother, "every fifteen days we would communicate on this app called IMO which is an app that lets you video chat and it works in Cuba. My mom would go to places to connect, because in
Cuba there's no Internet like here."

\section{DVL Profile of Sara and Theme: Low Visibility, Voice, and Gendered Expectations}

Sara, in her mid 20 and with a high school degree, was from Buenaventura, Colombia, a major port city. She said she migrated to "seek better opportunities" for herself and to support her single mother after she had a stroke. As an only child she declared: "so everything changed when my mom got sick, so it was up to me now." As a sex worker in Colombian night clubs, she continued that work in Panama for 6 months, and then in Chile, after she arrived a year ago. With the minimum wage in Colombia being so low, she declared that, "what I make here ends up being a lot in Colombia." Because her mother lost her job when she got ill, Sara went into sex work. She explained: "I can't feel proud of being a prostitute but I have changed a lot and Cod willing by next year I'll have my own house so everything has been for the better."

Surprised at how much money Sara sent home, her mother continually asked her about her job in Chile. Sara said, "I always talk to her and every day she asks me what I do here. I told her the other day 'they sent me the school papers' just to change the conversation. And then I tell her I work at a factory." Seeing her mother struggle was difficult for Sara and she didn't want to burden her religious mother further with details about her life. She said, "It would be disappointing, perhaps she would say that there wasn't any need for all this, of being in such position [a sex worker], and I know that, that at times, at not seeing her working, or seeing me in college the way she wanted to, those thoughts would cause her greater pain."

She said her mother wasn't "very good with technology, she's not familiar with it" and so they talked on the phone every day. Sara also 
didn't want her mother to see how tired she was when she picked up her early morning calls which woke her after long night shifts. Yet she wanted to be available. She said, "there are times she calls me, so I answer, that's why I never put the phone in silence or something like that...she calls, and I answer." When she couldn't talk to her she gazed at a photograph of her mother and held the rosary beads she gave Sara to remind her why she migrated. She said, "I don't wear it when I'm working, but that's what I have as memory from my mom." Sara took on extra customers to make more money to send her mother and she coordinated these meetings through voice calls. She told them, "just call me and schedule a time and we'll meet outside." Sara was selective about the content of her calls to both her mother and her clients to limit information about her to them. She managed her communication in a gendered way. She did this with her mother in particular like many immigrant daughters do through calling, remitting, listening, and supporting. Parreñas (2008) found that, "through the lens of transnational communication... women's migration does not initiate a complete shift in gender practices" (p. 81).

\section{Theme of low visibility across the participants.}

Sara's touching base with her mother, like for other participants, was a major reason for communicating and which connected to women's caring and emotional management roles. Touching base was part of emotionally managing family relations from afar due to their physical absence. Their phones and Internet access were necessities, not luxuries. Another Colombian participant felt responsible for her mother. She said: "I am the oldest. I am her support. I was the closest to her and that's the part I miss." Maintaining a parental role was another strong motivation to keep in touch. Mothers checked on their children all of the time and continued to be their children's mothers-at-a-distance. A Haitian participant who had left her son behind depended on the phone as the only method of mothering. She said, "I usually ask how my son is doing, is he alright, what's going on with him." While unable to parent her child directly, she sought a method to maintain her presence as his mother from afar and their conversations focused on him, not her.

\section{Scholarly and Educational Significance for Adult Literacy Practice}

The findings revealed the range of visual maneuverings by immigrant women in their communications with far-away family members in pursuit of co-presence. When immigrants try to protect older parents, ill relatives, and children from knowing about their difficulties as Sara's case illustrated, they withhold information that would be difficult for recipients to take in. Therefore, having low visibility was critical to their interactions as part of protecting them. They might need to keep secrets, at least temporarily, to ensure the survival of the relationship and use only their voice to reassure the family member left behind that they've not strayed too far emotionally. In this case, the absence of screens defines the interactions between family members. We found that those immigrants who wanted their families to know a lot about their lives, on the other hand, desired high visibility, like Carmen; they were frequent video callers and shared lots of daily information and had high self-disclosure about themselves, including talking about their feelings and exchanging photos, and they depended on screens to connect with family in a highly visible way. The other type of interaction was in the middle and demonstrated a great deal of selection of both content and viewing. Calls were made but they were episodic, like in Pilar's case. They sought 
contact with some family members, but not others, as Pilar did with her daughter, but less so with her mother. They also incorporated technological and geographical limitations. The act of calling itself was important to ensure the family left behind that the migrant members were OK. Pilar's calls also meant a commitment to continue to remit and she made sure the money she sent them was received and appropriately used. She rarely shared much with her daughter or her mother about her difficult street vending life. All three participants manipulated the ICTs for visual purposes to manage family relations and emotions through ICTs, and to create a sense of co-presence that worked.

The participants' ingenious navigation of their screens expands definitions of DVL, with new devices (smartphone platforms and apps), new populations (immigrants and transnational families) and for different purposes (personal communication). DVL, when embedded in transnational family communication, as I have shown, also expands both digital and visual literacies to include other sensory modes such as audio, especially when hearing and reacting to stories-that is the "environmental character" of multimedia communication (Krajina, 2009). Visual literacy researchers have focused more on surface issues, like 'reading' content and interfaces like, colors and lines. We have shown that there are deeper interpretations of DVL, when it comes to different populations and their socioemotional practices of communicating, including multilayered intimacy and relationships. Furthermore, this deeper definition of DVL expands digital literacy definitions, with its focus on populations of varying educational and literacy skill levels. We have shown that educational levels alone cannot determine the type or purpose of communication; regardless of their levels, the participants selectively navigated screens for different reasons, and to achieve a sense of co-presence in whatever way they could. And understanding how communication blockages occur with DVL is also important, due to the social and technological affordances on hand. The participants' creative uses of DVL through ICTs enables new interpretations of screen fluency focused on transnational family communication. On the surface, the screens appeared to offer sheer transparency. However, seeing family members from afar could become more visually complex. Screens, after all, can "stretch human interactions in time and space, and produce new spaces and forms of interaction" (Cruz \& Sumartoj, 2018, p. 336).

There were educational implications that could be gleaned from these findings for adult literacy and ESOL populations, regarding the importance of affordances, social practices, and informal learning. First it was clear that education levels of the participants had little to do with their digital literacy practices, except the number of affordances they inherited as part of their social classes/backgrounds. Pilar had a middle-school education and Sara had a high school education. However, they both owned phones and had enough service provision to make calls, and were savvy in navigating their transnational communique. Yet the family members with whom they spoke did not always have the same affordances. Carmen had a high level of education, lived in an urban area, and her parents had the resources to communicate so she did so more frequently, relying heavily on the screens to achieve a sense of co-presence. Assessing these levels of affordances would be critical starting points for effective practice in digital learning classrooms to ensure equity among students (in accessing ICTs), but also in accessing important community-wide services (Vanek et al., 2020). The first stage of DVL is to learn about students' practices and the ways they have been shaped by their affordances, both social and technological. 
Knowing for example, that students have to go to a library parking lot to access Wi-Fi to engage in remote interactions influences both digital curriculum and pedagogy.

The participants' DVL practices were focused more on the nuances of 'reading' expressions, and emotional subtleties through video or phone calls. In conjunction with speaking and hearing words and sounds to understand one another, they tried to glean meanings from the communication with their loved ones on screens, in order to achieve a sense of co-presence. From an educational perspective, what becomes important is the practice and emotional labor of reading faces, expressions, and gestures on screens, as well as background spaces, in order to effectively communicate. This emotional labor has been especially demanding during the global pandemic when remote/distance education has predominated through Zoom calls, transforming all students and teachers into talking heads, and where the embodied aspects of interacting can be missed. DVL practices in classrooms could focus on a deeper reading of communication through a literacy education that values "lifelong and life-wide learning” (Reder, 2020, p. 48); one which encompasses family learning, informal learning, and other types of literacy practices that fit within learners' life worlds. The emotional labor of image management conducted through DVL and ICTs is an important learning topic and may be a natural starting point for transitioning learners into formal settings.

This leads to implications for developing a deeper visual pedagogy in adult literacy and ESOL classes. This would mean emphasizing ways to navigate visual identities-ways to self-present, self-track, and navigate relationships from afar-along with discussing the emotional work of communicating and its meanings within different settings and contexts. This expands the learning content to include families and storytelling that enriches curriculum in adult education, ESOL, and community education. DVL can expand on photovoice and fotohistoria as well as digital stories of immigrants and their transnational families (Patiño, 2018; Yefimova et al., 2015). While a number of these educational projects are often used as interventions to improve services by making immigrant and refugee communities both seen and heard in the dominant culture, our perspective is based on the idea that transnational family communication can be a learned practice and developed through ICTs. Education that expands on this rich informal practice of families could also lead to new content (involving transnational family members in classrooms through technology) and peer learning among students.

Our focus on visuality provides evidence of immigrant women's agency and visibility as well as their adaptation struggles which challenges policy makers to address their needs and interests in the many roles they play in their lives, as workers, citizens, partners, mothers, and daughters. Larger questions remain, however, especially during the COVID crisis and its aftermath about the ways families interact at a distance, the ways policies play out with regard to human communication, and also the ways immigrant women deal with discrimination. These larger questions and issues need to be taken up by the adult literacy field and incorporated into practices. 


\section{References}

Agger, B. (2011). iTime: Labor and life in a smartphone era. Time o Society, 20(1), 119-136.

Avni, E., \& Rotem, A. (2016). Digital competence: A net of literacies. In Y. Rosen, S. Ferrara, \& M. Mosharraf (Ed.), Handbook of research on technology tools for realworld skill development (pp. 13-41). IGI Global. http:// doi:10.4018/978-1-4666-9441-5.choo2

Baldassar, L. (2008). Missing kin and longing to be together: Emotions and the construction of copresence in transnational relationships. Journal of Intercultural Studies, 29 (3), 247-266.

Baldassar, L., Nedelcu, M., Merla, L., \& Wilding, R. (2016). ICT-based co-presence in transnational families and communities: Challenging the premise of face-to-face proximity in sustaining relationships. Global Networks, 16 (2), 133-144.

Biocca, F. (1997). The cyborgs dilemma: Progressive embodiment in virtual environments. Journal of Computer-Mediated Communication, 3, 12-26.

Cabieses, B., Tunstall, H., \& Pickett, K. (2013). Understanding the socioeconomic status of international immigrants in Chile through hierarchical cluster analysis: A population-based study. International Migration 53(2), 303-320.

Cuban, S. (in press). Mapping southern routes of migrant women: A case study of Chile. Routledge.

Cruz, E., \& Sumartojo, S. (2018) Mobile screens and the public event: Screen practices at the Anzac Day Dawn Service, Continuum, 32 (3), 335-344.

Kovalchick, A., \& Dawson, K. (Eds.). (2004). Education and technology: An encyclopedia (Vol. 2, J-Z). ABC-CLIO.

Doña-Reveco, C. , \& Levinson, A. (2012). Chile: A growing destination country in search of a coherent approach to migration. Migration Policy Institute. http:// www.migrationpolicy.org/article/chile-growingdestination-country-search-coherent-approachmigration

Du Preez, A. (2018). Oversharing in the time of selfies: An aesthetics of disappearance? In B. Barbosa-Nieves \& C. Casimiro (Eds.), Connecting families: Information $\mathrm{B}$ communication technologies, generations, and the life course (pp. 81-95). Polity Press.

Dwyer, R. , Davis, I. , \& E. Emerald (2017). Narrative research in practice. Springer.

Gilhooly, D. , \& Lee, E. (2013). The role of digital literacy practices on refugee resettlement. Journal of Adolescent o Adult Literacy,57(5), 387-396. https://doi.org/10.1002/ jaal.254

Guillen, J. (2014). Digital literacies. Routledge.
Hannaford, D. (2015). Technologies of the spouse: Intimate surveillance in Senegalese transnational marriages. Global Networks, 15(1), 43.

Horst, H.A. (2006). The blessings and burdens of communication: Cell phones in Jamaican transnational social fields. Global Networks 6 (2), 143-159.

Jiménez, R. T., Smith, P. H., \& Teague, B. L. (2009). Transnational and community literacies for teachers. Journal of Adolescent $\&$ Adult Literacy,53(1), 16-26. doi:10.1598/jaal.53.1.2

Lankshear, C., \& Knobel, M. (Eds.). (2008). Digital literacies: Concepts, policies and practices (Vol. 30). Peter Lang.

Latour, B. (1999). On recalling ANT. The Sociological Review, $47,1-25$.

Licoppe, C. (2004). 'Connected' presence: The emergence of a new repertoire for managing social relationships in a changing communication technoscape. Environment and Planning D: Society and Space, 22(1), 135-156. https://doi.org/10.1068\%2Fd323t

Lynch, T. L. (2017). Soft(a)ware in the English classroom: Below the screen: Why multiliteracies research needs to embrace software. The English Journal, 106(3), 92-94. https://www.jstor.org/stable/26359297

Macgregor, M. (2013). New visualities, new technologies: The new ecstasy of communication. Routledge.

Madianou, M. , \& Miller, D. (2012). Migration and families and polymedia. Routledge

Madianou, M. (2016). Digital inequality and secondorder disasters: Social media in the typhoon Haiyan recovery. Social Media + Society, 1(2), 1-11.

Martin, F., Spalter, A., Friesen, O., \& Gibson, J. (2008). An approach to developing Digital Visual Literacy (DVL). College o University Media Review, 14(1).

Mirzoeff, N. (2006). On visuality. Journal of Visual Culture, 5(1), 53-79.

Nedelcu, M., \& Wyss, M. (2016). Doing family through ICT-mediated ordinary co-presence: Transnational communication practices of Romanian migrants in Switzerland. Global Networks, 16 (2), 202-218.

Neldelcu, M. , \& Soysüren, I. (2020). Precarious migrants, migration regimes and digital technologies: The empowerment-control nexus, Journal of Ethnic \& Migration Studies 89, 1-17. https://doi.or g/10.1080/1369183X.2020.1796263

Pahl, K. (2012). Every object tells a story. Home Cultures, 9(3), 303-327. 
Parchoma, G., \& Wright, S. (2011). Technologies for learning? An actor-network theory critique of affordances. Research on Mobile Learning Research in Learning Technology, 19, 247-258.

Palackal, A., Nyaga Mbatia, P., Dzorgbo, D. B., Duque, R. B., Ynalvez, M. A., \& Shrum, W. M. (2011). Are mobile phones changing social networks? A longitudinal study of core networks in Kerala. New Media \& Society, 13 (3), 391-410.,

Parreñas, R. S. (2005). Children of global migration: Transnational families and gender woes. Stanford University Press.

Parreñas, R. S. (2008). The forces of domesticity: Filipina migrants and globalization. New York University Press.

Patiño, C. (2018). Floating narratives: transnational families and digital storytelling. In B. BarbosaNieves \& C. Casimiro (Eds.), Connecting families: Information \& communication technologies, generations, and the life course (pp. 201-218). Polity Press.

Pink, S. (2009). Doing sensory ethnography. SAGE.

Reder, S. (2020). A lifelong and life-wide framework for adult literacy education. Adult Literacy Education, 2(1), 48-53.

Richards, P. (2013). Race and the Chilean miracle: Neoliberalism, democracy, and indigenous rights. University of Pittsburgh Press.

Riessman, C.K. (1993). Narrative analysis. SAGE.

Silva, S. R. (2012). On emotion and memories: The consumption of mobile phones as 'affective technology'. International Review of Social Research 2(1), 157-172.
Spalter, A.M., \& Andries, V.D. (2008). Digital visual literacy. Theory Into Practice, 47, 93-101.

Stefoni, C., \& Fernández, R. (2011). Mujeres inmigrantes en el trabajo domestico: Entre el servilismo y los derechos in Stefoni, Mujeres. 45-72. In C. Stefoni (Ed.), Mujeres Inmigrantes en Chile. Mujeres inmigrantes en Chile: ¿Mano de obra o trabajadoras con derechos? (pp. 45-72). [Immigrant women in Chile: Labor or workers with rights?]. Universidad Alberto Hurtado.

Tijoux, A. (2015). Racismo en Chile: Colonialismo, nacionalismo, capitalism. Polis 42, 7-13

UN DESA (2017). International migration report. https:// www.un.org/en/development/desa/population/ migration/publications/migrationreport/docs/ MigrationReport2017_Highlights.pdf

Vanek, J., Wrigley, H., Jacobson, E., \& Issleris, J. (2020). All together now: Supporting immigrants and refugees through collaboration Adult Literacy Education, 2(1), 41-47.

Wilding, R. (2006). Virtual intimacies. Families communicating across transnational contexts. Global Networks 6, 125-142.

Yefimova, K., Neils, M., Newell, B. C. , \& Gomez, R. (2015). Fotohistorias: Participatory photography as a methodology to elicit the life experiences of migrants. Proceedings of the $48^{\text {th }}$ Hawaii International Conference on System Science. 